\title{
Identity Crisis in Reza Ghasemi's The Nocturnal Harmony of Wood Orchestra
}

\author{
Niloofar Mansuri ${ }^{1}$, Samira Sasani ${ }^{2 *}$ \\ Shiraz University, IRAN \\ e-mail: niloofar.2999@gmail.com ${ }^{1}$, samira.sasani21@yahoo.com ${ }^{2}$ \\ *corresponding author
}

\begin{abstract}
Migration, this multifaceted phenomenon, has always been an important concept in different domains such as art and literature. What impacts migration has on human psychology can be well elaborated on using the tool of characterization in stories. Among these impacts, the one regarding identity is probably of highest importance. Therefore, the literature of diaspora can be a field for exploring the process of identity refashioning. What the present study aims to elaborate on is Reza Ghasemi's The Nocturnal Harmony of Wood Orchestra and the way identity crisis is manifested in and handled by the characters in this novel. The analysis is grounded on Homi Bhabha's concept of Third Space but to specifically analyze the challenges that immigrant characters face in this liminal location, Yuri Lotman's cultural idea of semiosphere is also incorporated.
\end{abstract}

Keywords: Identity Crisis; Literature of Diaspora; Reza Ghasemi; Third Space; Yuri Lotman.

\section{INTRODUCTION}

"To find out the truth I rely on my own thoughts and imaginations rather than what I see as the reality. You know it well that what people say and do is nothing but a veneer to cover what they think about". (Ghasemi, 2005, p. 65)

This is a manifestation of the overall attitude of the narrator in The Nocturnal Harmony of Wood Orchestra; drowning himself in the melancholic world of imaginations, dreams, and thoughts. This narrator acts like Ghasemi, the author of the novel, who not only suspends the audience between imagination and reality, but also plays with the concept of time and by adopting an amount of intertextuality, complicates the novel, turning it into a multi-layered story.

The novel, narrated by Yadollah, a paranoid hallucinating young man who has fled Iran after the Islamic Revolution, relates the story of the forlorn and lackluster life of a group of Iranian exilic immigrants who reside in a French landlord's building in Paris. With the entrance of a new Iranian guy called Prophet, who introduces himself to be a representative of God, the building faces a disastrous crisis; a crisis which leads to the murder of Yadollah by Prophet.

The concept of time is not linear in this novel and as we go through the book, the whole story is gradually completed in the form of a puzzle. The vague and phantasmagoric nature of the story is little by little decoded and it is eventually revealed that Yadollah, who talks to the angels of the grave throughout the story, is dead now and is also transmogrified into the landlord's dog, Gobbic, from whose point of view parts of the story are narrated.

The Nocturnal Harmony of Wood Orchestra, an example for the literature of crisis, provides the audience with a description of the baneful life of the Iranians in diaspora. As Nanquette stipulates, since the Islamic revolution most of the Persian diasporic publications "could not be exported to Iran due to the severing of ties between Iran and its diaspora, both on the physical and financial levels," however, The Nocturnal Harmony of Wood Orchestra, originally published in Persian and then translated into French and English, was an exception (2017, p. 161). The book "received positive reviews from the Iranian press and was generally well received in Iran, winning the Hooshang Golshiri Prize for best first novel in 2002" (Nanquette, 2017, p. 161). It deals with the feelings of loneliness, exhaustion, nihilism, and depression in the characters and depicts the crisis of identity in them. However, it is underestimation if we consider this novel as only a story of the immigrants' lives. As Gholami (2002) mentions in his "The God of Destruction", more than immigration and its consequences, Ghasemi, in his book, elaborates on the bafflement of the whole humanity in today's modem world (p. 7). 


\section{THIRD SPACE IDENTITY CHALLENGES AND THE CHARACTERS' REACTIONS}

Leaving one's own country an immigrant will experience diaspora, and this will bring ambivalence and take away pure identity. In fact, as Zohdi (2018) contends, "'home' plays a crucial function in stability of one's identity. Therefore, 'unhomeliness' can be the main cause of a merged or even a lost identity" ( $p$. 147). The reason why home stabilizes the identity while unhomeliness destabilizes it is highly related to Lotman's concept of cultural semiosphere. Lotman in his Universe of the Mind defines semiosphere as:

The semiotic space necessary for the existence and functioning of languages, not the sum total of different languages; in a sense the semiosphere has a prior existence and is in constant interaction with languages. In this respect a language is a function, a cluster of semiotic spaces and their boundaries, which, however clearly defined these are in the language's grammatical self-description, in the reality of semiosis are eroded and full of transitional forms. Outside the semiosphere there can be neither communication, nor language. Of course, the single-channel structure is a reality (pp. 123-124).

When immigration occurs, there is a shift from the semiosphere of the motherland to that of the host land. It creates a problematic situation for the immigrant. Fallah, et. al. mention that "identity-makers (sic) elements lose an important part of their power and influence after withdrawal from the sphere of their Semiosphere" (p. 19). It is also noted that facing the identity crisis, the immigrant is subjected to three different choices. The first one is to show loyalty to the motherland semiosphere and approve of its elements; the second is to try to make a balance between the identity-maker elements of both semiospheres; and the third option is to devaluate and marginalize the motherland semiosphere's elements and replace them with different discourses of the host land. The third option may lead to perplexity in the immigrant's mind and might even bring about loss of identity (pp. 25-26). The confrontation of two different lands includes within itself the confrontation of two different semiospheres with all their various elements. As Khodayi (2011) mentions, the immigrant subject might choose any of the two ways of accepting or rejecting the tenets of the host land cultural semiosphere, but it does not differ which one of the two ways he/she opts; the very challenge, itself, brings about a need for reconsideration of the motherland values and axioms. This rethinking may lead to the betterment of the situation for the subject of diaspora or it may, instead, add to the society and identity-related problems (p. 42).
This shift of cultural semiosphere and its consequent crises are in line with what Bhabha considers as hybridity occurring in Third Space and what the Third Space subject ought to do to reach a hybrid consciousness. Based on Bhabha's theory, the identities of the colonized are formed in the third space of enunciation. This third space is where the two different cultural traditions and potentials of power encounter and try to reach some kind of negotiation or translation. While this third space provides the subjects with an opportunity of hybridity and gaining power, it depends on the very subjects of diaspora whether to reach the consciousness of this hybridity and set negotiations between the two cultures or not. Bhabha in The Location of Culture uses the image of the "stairwell" to show the free shifts of the immigrant subject (p. 4). However, not all subjects located in Third Space reach that kind of hybrid consciousness Bhabha refers to. They may, instead, panic at their displaced position. Based on how these immigrant characters react to their liminal situation, they are divided by Borhan to three categories of "nativists", "assimilationists", and "the hybrid". They respectively stick to the memories of the past, evade from thinking about the past, and try to come to terms with their existential crisis and refashion their identity based on the new discourses they face (Borhan, 2016, p. 7).

As Rutherford (1990) contends, when a new situation (which is here the third space of enunciation) formulates itself, it may demand that the immigrant should translate his/her principles, rethink them, and extend them (p. 216) and if that immigrant is not able to do what mentioned, the hybridity creates a dual life and a sense of double vision or double consciousness which might lead to a merged or even a lost identity in him/her.

Similar to what Venn (2009) mentions in his analysis on Tsitsi's Nervous Conditions, in Ghasemi's novel as well "Loss of one kind or another haunts all the main characters, all involving displacement as well as more intimate and intractable losses" (p. 14). The main reasons for these losses are the oscillation between motherland and host land semiospheres and the consequent identity crisis whose manifestations in the novel are the characters' different psychological disturbances and mental illnesses. According to Khayef, Nickfam, \& Behin (2015), these immigrant characters have gone away from the original self and have destroyed their true essence and nature in order to create a false, fake self (p. 8). To analyze the characters' identities, Borhan's tripartite model of subjectivity is used. This model is based on Bhabha's concept of third space in which the subject of diaspora is free to turn toward any model of subjectivity; nativism, assimilationism, or hybridity. 


\section{SEYYED, THE ASSIMILATIONIST}

Among all the immigrants in the novel, Seyyed is the one who shows, more vividly, his lack of interest in clinging to the past and being satisfied with the monotony of life. He, when confronted with the hybridity and inbetweenness of Third Space, shows tendency toward putting the nostalgia aside, going forward, changing the current life conditions, and of course assimilating into the host land cultural semiosphere.

From the beginning of the story the narrator, now and then, refers to different instances of Seyyed's high ambitions which are in line with his inclination toward assimilation with a host land which is more modernized than his own motherland. He greatly welcomes new opportunities and new communications with the host land people and this can be a sign of his thirst for change and for constructing a new life. In the first chapter, the narrator refers to this characteristic of Seyyed by noting, "It was enough for him to just enter a gathering; at the very first moment he started talking to you in such a way that after only half an hour you felt as being friends of each other for a thousand years" (Ghasemi, 2005, p. 30). Seyyed, in fact, always finds potentials in the other side of the conversation that can help him/her improve (Ghasemi, 2005, p. 31). Showing such behavior toward the host land people, Seyyed tries to find the way to their hearts and make them accept him as one of themselves.

The liminal situation of the third space of enunciation is what Seyyed intends to pass over because he has not reached the consciousness of this hybridity. He, in fact, does not miss any chance of getting involved with the host land atmosphere; for example, he often goes to restaurants instead of having meals at home and even usually goes out to different cafes for such trivial purposes as relieving bowels. In spite of Yadollah, Seyyed is always ready for confrontation with new people and is always smiling and good-tempered in case of such confrontations.

The always smiley face and the kind and welcoming attitude toward host land people, in line with his conversation habits, are strategies by Seyyed to facilitate and accelerate his process of assimilation with the host land semiosphere; regardless of the fact that trying to marginalize the motherland semiosphere's elements and instead replace them with those of the host land might bring about perplexity of mind and even loss of identity (which is observed in Seyyed in descriptions of the way he introduces himself to others or the way he is desperately stuck between his matrimonial life and extra marriage affair).
Seyyed's decision of being the first one to remove the separation between his room and the one next to it can be indicative of his leading tendency for assimilation with the western host land one of whose cultural semiosphere's elements is lack of the privacy the eastern people look for. His decision can also be considered as a superficial manifestation of his ambitious nature, but what evidently shows this characteristic in him is in the first chapter of the book where the narrator claims,

Lowness was not defined to Seyyed's soul. He used to hate petty work, petty income, petty origins, and any other petty thing which lacked multitude ... He wished magnanimity not only for himself but also for others as well. That's the reason why he used to introduce me to the others as the greatest painter of our motherland, while I was just a mere house painter. (Ghasemi, 2005, p. 32)

The quote mentioned above can also be a sign of Seyyed's lack of interest in his native origins, as he seemingly considers them as petty. Magnanimity, to Seyyed, does not mean being Iranian. Yadollah also refers to this escape of Seyyed from his origin and also to his desire for greatness which little by little leads to assimilation with not only France but also other parts of Europe as the broader host land; "Being from Ghom, a small town in Iran, when coming across French people, who pronounced " $r$ " as "gh", he easily pretended to be from Rome, Italy" (Ghasemi, 2005, p. 33).

Seyyed believes that such claims can add to his greatness in the eyes of the host land people and make them accept him as one of themselves. Therefore, what begins so simply, later gets so serious that ends in his denial of his own identity; "In this way the day when he changed his nationality, he changed his name to Alexander and little by little he even tried to find evidences in his paternal genealogy proving that his ancestors belonged to noble families of Italy" (Ghasemi, 2005, p. 33). This is probably the utmost manifestations of the loss of identity in Seyyed, a Third Space subject who, when confronted with his liminal situation, does anything to marginalize and devaluate his motherland cultural semiosphere. To highlight this change of name Yadollah, later, refers to Seyyed as Seyyed Alexander; and this is a funny instance of the cases in which the Third Space subject embarks on mimicking the host land natives in order to be a part of the authoritative power however with a strategy which is not effective enough.

Nevertheless, name is not an issue only to Seyyed; it appears as a challenge to other immigrant characters as 
well. In fact, one of the reasons why in the novel the Iranian characters are alienated from themselves can be the fact that their names have changed again and again. This recurrent name change can be traced back in the Iranian political refinements that occurred during a particular time period (1990's). The migrant Iranians residing Europe were terribly afraid of those happenings and were doubtful about each fellow immigrant's real identity.

This choice of different names, which is in direct relationship with characters' identity and sense of self, is referred to in the article entitled "Investigating Modernistic Elements in Nocturnal Orchestra of Woods": "Every day, characters of the novel choose a new name in order to get rid of their wistful sweet memories in homeland country but they are unable to make it. As Jung puts them 'Forgotten memories never disappear... and after years of oblivion, they can often appear completely at any time' (Jung, 1999:40). It can be representative of identity crisis too" (Khayef, 2015, p. 8).

Another challenge observed in Third Space is marriage. The fact that Seyyed, in opposition to Yadollah, marries a European girl is another sign of his inclination toward the host land. While this acceptance of a partner from another culture might appear as a sign of hybridity, Seyyed's matrimonial life which does not follow what is considered as the normal pattern in his motherland and is, instead, a blind imitation of the host land cultural semiosphere, indicates assimilation rather than hybridity. In the second chapter of the book the narrator touches upon that and notes that Seyyed and his wife live independently from each other and are used to being separated for a while (p. 52).

In addition to his different matrimonial life, the fact that Seyyed keeps his extra marriage affair is again something that can be attributed more to the western host land culture rather than that of the motherland semiosphere and therefore can be an implicit indication of his tendency for assimilation with the immoralities of the western host land semiosphere. Seyyed's liminal situation in-between his wife, with whom he does not seem to have a strong matrimonial bond, and Raana, for whom he does not experience stable emotions, can be considered as one of the sources of the crisis he suffers from; the identity crisis which leads to his tendency for assimilation with the host land cultural semiosphere. Seyyed can be considered as an embodiment of the Third Space subjects who do not approve of the liminality; the ones to whom many factors belonging to the host land cultural semiosphere are so intriguing that propel them toward distancing themselves from the motherland semiosphere and its culture.

\section{YADOLLAH, THE NATIVIST}

From the very beginning chapter of the story when the church bell rings and Yadollah feels that his small planet is out of its orbit, the readers understand that they are going to deal with a narrator who does not easily accept and welcome changes. To him any minor change acts as a danger and can put his comfort zone at risk; let alone the ones regarding Third Space and its hybrid situation. Living in Iran's time and the lapses in continuity, his psychological condition or better to say the intentional technique, are evidences for the fact that Yadollah, when placed in Third Space and confronted with liminality, does not reach hybrid consciousness and instead prefers the motherland. Paris time is one of the host land semiosphere's codes he does not accept conforming to and the psychological condition including lapses in continuity, followed by amnesia, is the resistance strategy he opts.

In Yadollah's life, time is a different concept from what it is in others' lives. While he has migrated to the western hemisphere of the earth he lives on the eastern hemisphere's time. In the first chapter of the book he refers to it and mentions how in his previous residences, others had problems with his nocturnal wakefulness and diurnal sleep but now Schmitt and the neighbors show no dissatisfactions to his twelve-hour time difference with the semiosphere they all live in. This compatibility of the neighbors, who are mostly immigrants, with the man who lives in Paris but on Tehran time, shows that this sense of oscillating between two parallel times or more generally two semiospheres is not confined to the narrator's life and might probably exist in the other migrants' diasporic lives as well. This feeling of inbetwenness is one of the factors that deprive them of a sense of belonging and therefore negatively affect their identities.

What mentioned is not the end of time-related difficulties. Time is in different ways problematic to Yadollah, the story's main character. He cannot accept the host land time and refers to it as "the frozen exilic time", to whose pains playing chess can act as a temporary balm (Ghasemi, 2005, p. 72). Another one of his strategies for not facing the new semiosphere's time is the psychological condition he refers to as the lapses in continuity. These lapses occur as a result of his deep contemplations during which he gets drowned in a sort of amnesia and forgets about his recent actions. As Kavianpour (2018) mentions in his article, Yadollah, himself, has chosen this psychological condition in order that he can forget about the confrontation of the past and the future and in fact crystallize the host land's time and prevent it from passing. These lapses in continuity act as drugs to him (Ghasemi, 2005, p. 10). They really act as drugs; while 
seem to calm him down temporarily, in fact, worsen his conflict with and rejection of the time difference between the two semiospheres.

This amnesia is considered as an intentional technique or, as Foucault labels, strategy of resistance against the host land because the time acts as a manifestation of the controlling power of the host land of whose authority Yadollah decides to evade. Foucault does not consider power relationships as being imposed top down. He speaks of power as "something that circulates" (1980, p .98) and as being "produced from one moment to the next” (1978, p. 93).

Another factor with which Yadollah, as many other subjects of diaspora finds a challenge is religion. In confrontation with the new cultural semiosphere and its dominant religious tenets, the immigrant, in most cases, starts questioning the theological beliefs prevalent in the motherland semiosphere; however, to Yadollah this is not exactly the case.

The narrator reveals the fact that in spite of all changes, religious beliefs are not easy to forget even for a subject of diaspora who has migrated years ago. Therefore, the challenge of religion is still present for Yadollah and he has not been able to solve and handle it. He, again, refers to it by noting, "It was then and there that I recognized my former beliefs, while not keeping their precise contents, still survive in some approximate forms" (Ghasemi, 2005, p. 28). Examples of such beliefs that remain with Yadollah include the doomsday divine punishment and the intimidating investigation of Munkar and Nakir (the Denied and the Denier, two angles of the grave) at the burial night which are engraved on his soul since childhood and even now, in the third space come to him as torturing nightmares.

The other Third Space challenge the immigrant characters of the book experience is the liminal situation which happens as a result of the difference in western and eastern emphasis on privacy. In other words what Yadollah mentions that they experience in the host land cultural semiosphere is almost a lack of privacy. Privacy can be defined as a fundamental human right for people to lead their lives in a manner reasonably secluded from public scrutiny and therefore feel a basic level of security guaranteed. Whether privacy is protected or not, has an influential role in people's mental health. In The Nocturnal Harmony of Wood Orchestra, the building where the Iranian immigrants live does not provide them with that much of privacy which is considered as necessary in eastern culture and this is in fact annoying to the characters as their sense of security is shattered. In the second chapter, Yadollah, the narrator of the book, gives a description regarding how open their building is:

... our tenement's door was always open. The problem was not only the lack of a lock; it could not even be closed. In winters the stairs were so loaded with the homeless, and the drunken vagrants and tramps that you had to act as mountaineers; looking for a safe place for each step you took. (Ghasemi, 2005, p. 74)

This lack of privacy is not only about Schmitt's tenants in relation to the people outside. It is also about the residents of different rooms in relation to each other. There is a part in the book where Yadollah talks about an annoying recognition moment when he understands about the possibility of being easily scrutinized and heard by the neighbors: "And for the first time I found out how thin the walls were for the curious ones; found out how unvarnished we were in front of each other, while we thought we were keeping our private lives within the borders of our rooms and away from the others' looks" (Ghasemi, 2005, p. 61).

One of the consequences of not dealing with this liminal situation is that Yadollah retrospects, inclines toward loneliness, and does not seem to be able to get rid of his inner inconsistencies and the depression he entangles with. He prefers to sit alone in his room the whole day and get busy painting. In different parts of the story he emphasizes on this loneliness and also his thirst for that, as a result of the unsettled mind the Third Space hybrid situation has offered him. Therefore, as Mousavi mentions in his thesis about the narrator of the novel, Yadollah does not reach the phase Bhabha calls hybridity (p. 106).

The situation referred to is not only observed in Yadollah. Prophet as a second example; is a shy, introvert, and secluded guy who does not make communications and does not go out of his room unless in case of emergency needs. He has not, in fact, come to terms with the in-between situation. Ali, as another one, even turns toward mysticism as a consequence of the ubiquitous loneliness and the love break down that worsened it. Raana feels this loneliness as well and this is the reason she looks for a partner and oscillates between Yadollah and Seyyed to find refuge in one. However, the real nature of what Yadollah and also these characters of the story experience is not solitude; it is isolation. The difference between solitude/being alone and isolation/loneliness is in fact a delicate issue. Rokach (1990) in his "Surviving and Coping with Loneliness" refers to this difference by noting: " . . . solitude, unlike loneliness, is often referred to as a positive, pleasant experience that is conducive to replenishing one's energy and 
resources, and that affords one the time and space to reflect, be creative, or just enjoy rest" (p. 42). This difference between the two concepts and the effect the latter one has on personal identity is more elaborated on when in his article Ram N. Singh (1991) quotes Moustakas,

A person who is alone does not feel abandoned and feels no lamentations for losses in life. Being in touch with himself, he is ablaze with energy and excitement. The lonely person's emotions are liable, fluctuating and charged with poor self-esteem. The alone being in touch with his inner self abounds in energy and enthusiasm. The lonely feels lazy, left behind and loathful to the society; whereas, the alone may learn to approve of himself and others ... Being in touch with himself, the [alone] individual is open-minded, optimistic and eager to get in touch with his optimum strength. He feels being an owner of himself. The lonely person, on the other hand, feels obscure, obliterated and an oddity to himself. (pp. 110111)

The latter situation which appears to occur to the story's subjects of diaspora and even adored by them, for sure, is not a healthy situation and might, as mentioned in the quote, cause irreparable damages to the identity, one of which might be a lower self-esteem. As Singh contends, "Loneliness is the greatest dynamic behind depression, anxiety, guilt and sense of self depreciation. It is not only painful but fatal at times (p. 110).

In addition to whatever manifestations of Third Space challenges Yadollah experiences, there is this major crisis which is somehow inclusive of all the ones previously mentioned and it is that of the in-between identity. Yadollah is not satisfied with this inbetweenness and does not accept to refashion his identity based on the hybrid situation he has; he instead reveals his tendency for self-destruction in order not to conform to the formation of a new identity. The mirror disease Yadollah suffers from can be considered as a manifestation of this tendency for self-destruction and self-denial in Yadollah. As Leila Sadeghi (2004) notes in her article in Kelk magazine, this mirror disease, as one of the main motifs of the novel, is a disease of identity (p. 46). It is a mental condition in which the narrator is not able to see his reflection in the mirror. The fact that at the end of the story the narrator is able to see his reflection in the mirror is indicative of the fact that resistance, in the book appears as useless and gives the immigrant no success in dealing with his immigration.

\section{LACK OF A HYBRID CHARACTER}

While the other immigrant characters of the novel, including Raana, Prophet, Fereydoun, Sheriff and his wife, and Ali, do not appear as strict nativists or assimilationists and just wander in the space in between, they do not reach hybridity either. Raana is a beautiful and smart woman but at the same time a weak girl who finds her self-confidence only through the support she receives in relationships with guys. This is, in fact, her strategy to come to terms with and compensate for the empty life she has in diaspora. However, she never succeeds in that, just oscillates between Yadollah and Seyyed, and finally commits suicide.

Prophet deals with hallucination and paranoia. $\mathrm{He}$ believes himself to be the agent of God. He is supposed, at first, to be a religious, faithful man, but on the contrary, he reveals to be a killer. He is the most anarchist and revolutionary character of the story who never seems to be content with his life in diaspora. He also has Fereydoun and Sheriff on his side in getting paranoid towards other Iranian immigrants. They can neither balance their own personal identities nor create good interpersonal relationships with other immigrants. The result is the oscillation and personal identity crisis, as well as a bad impression of the cultural identity of Iranians to such a native as Dr. Francois Schmitt, the landlord; "He had gained a good knowledge of the Iranians during these years. He knew that none of them was eager to see the other and anyone who came to him was trying to make mischief to another" (Ghasemi, 2005, p.180).

Ali's seclusion and inclination toward mysticism, Prophet's fanatic character and disastrous illusionary mind, and Raana's oscillation and suicide are all outcomes of the identity crises the immigrant characters of the book suffer from. Therefore, the novel, when analyzed through Borhan's tripartite model of subjectivity, does not provide us with any immigrant characters who reaches hybrid consciousness. An immigrant who reaches such a consciousness, is almost in peace with his/her situation and does not suffer from serious crises but in this novel none of the immigrant characters is so. In other words, none of them appears to be successful in dealing with the inbetweenness they experience in Third Space.

This unsuccessfulness in reaching the stage of hybridity is not something only problematic to the immigrant. It affects his/her relationships with other fellow immigrants as well. It is observed throughout the novel that immigrants can neither balance their 
own personal identities nor can they create good interpersonal relationships with other immigrants.

\section{CONCLUSION}

Being placed between the past motherland semiosphere and that of the present host land, Ghasemi inclines toward the past and considers the motherland nostalgia as impossible to avoid. In the ninth book review session of Raviun, Ghasemi refers to the effect of his past on his present literary work and mentions that he believes his novel to be a product of different psychological conditions he has experienced both before and after the Islamic Revolution. These conditions, similar to what occurs to Yadollah, the narrator, include fear, paranoia, and self-destruction. He states that to him the immigration, itself, is a form of self-destruction because when a person immigrates, he, for sure, loses much more than what he might gain. The author's pessimism toward immigration and its consequences is also manifested in how he portrays the identities of subjects of diaspora in his novel. There are no hybrid characters in the novel whose technique in handling the inbetween situation can be considered as a role model for the other immigrants. Moreover, there is no sense of success in either Seyyed or Yadollah who are respectively assimilationist and nativist. To put it another way, although Reza Ghasemi as an immigrant author is nostalgic about the past and appears as a nativist, he does not intend to convey the message that nativist immigrants, in dealing with the immigration process, feel better than the assimilationists. There is a part in the first chapter of the book where the narrator, as a nativist, compares himself with the assimilationist Seyyed and mentions that in spite of their personal differences in making communication with others and the attitude they have taken toward the host land, neither of them has achieved success in his life (Ghasemi, 2005, p. 31).

From what mentioned, it can be inferred that to Reza Ghasemi immigration is still a challenge. $\mathrm{He}$, as himself mentions in his interview with Mandanipour, rarely goes out and as a result has lost so much of a firsthand communication with the outside European cultural semiosphere for some years. The outcome is that in his novel he portrays the immigrants' lives as nightmares.

Considering the classification for Iranian authors of the literature of diaspora, to categorize Reza Ghasemi is a little bit complicated. He wrote the novel in the year 1996, which is related to the second phase; however, as he is among the authors who migrated immediately after the Islamic Revolution and later wrote his book, as he claims, under the influence of those years, that would be more appropriate to place him in the first category of immigrant authors with which the features of his novel correspond better.

Furthermore, Ghasemi is probably one of those exiles who are described by Hamid Naficy in "The Making of Exile culture". Naficy (1993) states, "On the one hand, they refuse to become totally assimilated into the host society; on the other hand, they do not return to their homeland - while they continue to keep aflame a burning desire for return. In the meantime, they construct an imaginary nation both of the homeland and of their own presence in exile" (P. 17). Nostalgia is the feeling these exiles experience.

According to Naficy (1993), what differentiates these exiles from people in diaspora is that "exiles' primary relationship is not so much with various compatriot communities outside the homeland as with the homeland itself', and this is vividly observed in Reza Ghasemi (P. 17). He lives in France but is still mentally preoccupied and more in touch with Iran and its traditions rather than the European cultural semiosphere of the host land. Hashemi thinks that "this novel does not show that much explicit elements of literature in Diaspora; however, there is an undeniable sense of loss and the need for belonging (2017, p.76).

While Reza Ghasemi might not be successful as an immigrant who should cope with the shift of semiosphere and the inbetweenness of Third Space, he is successful as an author who writes about this shift. By success it is meant a literary one which has nothing to do with the author's attitude for writing of immigration. Ghasemi, as an author, is standing between two spaces, but his voice is not left in the void of Third Space; it reaches both the first and the second spaces and is received relatively well, specifically in the motherland. While it cannot be denied that Ghasemi does not that much contribute to the introduction of Iranian culture to the western cultural semiosphere, he does not misrepresent it either and this is good when compared to many other works of the Iranian literature of diaspora. On the other hand, Ghasemi does not represent the host land as kind of a utopia; in a well-organized, post-modern, fictional framework he represents the crises that migration causes to a subject of diaspora and while showing nativist inclinations, tries to stay impartial and these are all the reasons which make the novel a successful literary work within the Iranian literature of diaspora. In other words, regardless of whatever view toward immigration Ghasemi takes, he is still able to write a migration book which is literarily rich, does not get political by misrepresenting home or host society, and is almost well-received in both cultural semiospheres. 


\section{REFERENCES}

Bhabha, H. K. (1994). The location of culture. London: Routledge.

Borhan, A. (2016). Third-Space encounters and the possibility of resistance in selected multi-ethnic American novels, dissertation, Shiraz University, Shiraz.

Fallah, G. A., Sojoodi, F., \& Baramaki, S. (2017). The Challenge of Identity-Makers Elements of Motherland and Host land in Migration InterDiscourse Spaces in Migration Persian Literature Novel. Language Related Research, 7(5), 19-42.

Foucault, M. (1978). The history of sexuality. New York: Pantheon Books.

Foucault, M. (1980). Power/knowledge: Selected interviews and other writings, 1972-1977. C. Gordon, (Ed.). New York: Pantheon Books.

Ghasemi, R. (2005). The Nocturnal harmony of wood orchestra. Tehran: Niloofar.

Ghasemi, R. (2013, May 27). Philosophy and novel take different forms of intellectuality. Interview by Shahriar Mandanipour. The Center for the Great Islamic Encyclopedia. Retrieved September 10, 2018, from www.cgie.org.ir/fa/news/ 3153.

Ghasemi, R. (2013, Nov. 8). Encounter with the book. Hamid \& Christina Moghadam Program in Iranian Studies, Stanford University. Retrieved September 10, 2018, from youtu.be/PtpzUihsqg0.

Ghasemi, R. (2018, March 16). Raviun ninth book review session, Via Giambattista Bogino 9, Turin. Retrieved January 22, 2019, from youtu.be/4smj7j35hUY.

Gholami, A. (2002). The God of destruction. Hambastegi. 613, 7.

Hashemi, M. (2017). No Hero and No Faces: The Postmodern Antihero in Reza Ghasemi's The Nocturnal Harmony of Wood Instruments. Persian Literary Studies Journal, 6(9), 59-80.

Jain, J. (2015). The diaspora writes home: Subcontinental narratives. Jaipur: Rawat Publications.

Jin, X. (1998). Across an ocean of words. Interview by John D. Thomas. Emory, 74 (1), 16.

Kavianpour, S. (2018). A post-modern narration of the dead's life. Etemad, 4057, 10.

Khayef, E., Nickfam, R., \& Behin, B. (2015). Investigating modernistic elements in nocturnal orchestra of woods. European Journal of English Language and Literature Studies, 3(6), 1-10.

Khodayi, N. (2011). Presentation of the conflicts of society and identity in German migration literature. Research in Contemporary World Literature, 15 (60), 41-60.
Lotman, J. M. (1990). Universe of the mind: Semiotic theory of culture. Bloomington and Indianapolis: Indiana University Press.

Morrison, B. (2015, Nov 27). Too much information? The writers who feel the need to reveal all. The Guardian, Retrieved from: www.theguardian. com/books/2015/nov/27/confessional-writingmemoirs-writers-feel-need-reveal-all.

Mousavi Iraie, M. S. (2017). An Analysis of Migration Literature's Motifs in Reza Ghasemi's The Nocturnal Harmony of Wood Orchestra and Abbas Maroufi's Completely Special, [Unpublished master's thesis] Semnan University, Semnan.

Naficy, H. (1993). The making of exile cultures: Iranian television in Los Angeles. Minnesota: University of Minnesota Press.

Nanquette, L. (2017). The Circulation of Iranian Texts around the World: The Appearance of a Transnational Iranian Publishing Industry?. Australian Humanities Review, 62, 157-169.

Rastegar, E. (2012). From the invisible gardens. BBC Persian Television, Retrieved February 25, 2019, from youtu.be/oKx37CLB4pg

Rokach, A. (1990). Surviving and coping with loneliness. The Journal of psychology Interdisciplinary and Applied, 124 (1), 39-54.

Rutherford, J. (1990). Identity: Community, culture, difference. London: Lawrence \& Wishart.

Sadeghi, L. (2004). Comparative research between the nocturnal harmony of wood, slaughterhousefive, and blind owl. Kelk. 29 (149), 43-47.

Shahsavari, M. H. (2013, Dec. 16). The Eighth analysis session of best contemporary works of Persian Literature. Tehran Book Club, Arasbaran Cultural Center, Retrieved March 20, 2019, from www.mehrnews.com/amp/1767202

Singh, R. N. (1991). Loneliness: Dynamics, dimensions and many faces. International Review of Modern Sociology, 21 (1), 109-120.

Tafreshi, M. L. (2010). Post-colonial studies in the immigration literature. Political Science Quarterly, (10), 211-222.

Venn, C. (2009). Identity, diasporas and subjective change: The role of affect, the relation to the other, and the aesthetic. Subjectivity, 26(1), 3-28. doi: 10.1057/sub.2008.37

Zohdi, E. (2018). Lost-identity; A result of "hybridity" and "ambivalence" in Tayeb Salih's Season of Migration to the North. International Journal of Applied Linguistics \& English Literature, 7(1), 146-151. doi: 10.7575/aiac.jjalel.v.7n.1p.146. 